\title{
Consumer's Purchase Intentions for E-Grocery Shopping in India
}

\author{
Himanshu Budhiraja ${ }^{1}, K_{\text {Kanav Mittal }}^{2}$ \\ ${ }^{1,2}$ (Research Scholar, Chitkara Business School, Rajpura, India)
}

\begin{abstract}
Online grocery business is at emerging stage in India. Online retailers need to analyze different factors that affect consumers purchase intentions towards online grocery shopping. It is also observed that buying behavior of consumers for online grocery shopping is totally different than buying from physical markets. Online grocery model fulfills consumers' need and help them to save their time and effort. The purpose of this paper is to throw a light on different types of e commerce models. The paper also tries to understand the demographic profile of the customers who groceries through online mode, reason to purchase groceries online and satisfaction level of customers buying groceries online.
\end{abstract}

Keywords- E-grocery, Models, Consumers, Shopping.

\section{INTRODUCTION}

Food and grocery is the basic daily need of any household. Online grocery business is at emerging stage in India. This kind of model has gained popularity in tier one cities like Delhi and Mumbai, but still it is a long way to go. As of now people in India are not much familiar with this kind of model.People in the country prefer buying items like groceries, fruits and vegetables by physical comparison of price and quality. In this type of culture prevailing in the country, it is very difficult to make this kind of model popular in Indian markets, but on the other side other e- commerce businesses are gaining much popularity in the Indian markets and e-commerce grocery industry is in its introductory phase .So, this presents a great opportunity for any firm to enter the e-grocery space.

[1] Grocerye-tailing in India is a largely unorganized space and poses a big challenge in terms of stiff entry barriers. The traditional methods of inventory and logistics management call for intense cash-burning - a business condition most of the bootstrapped Indian start-ups fail to meet. [2]is of the view that living alone, away from family, is a tough task. Other than that, one has to take care ofeveryday domestic hassles.Tiring 12 hour shifts in the office and transportation distress that leave you feeling so exhausted that the prospect of cooking seems like torture. In such a scenario, it is difficult for young Indian professionals to shop for grocery.With the current mushrooming of online grocery portals on the digital medium, one might wonder upon the feasibility of these ventures.[3] points out that Current e-grocery model are based on the consumer making his or her purchase over the Internet, and the egrocer delivering the purchase to the household. However, there are numerous opportunities for innovative new services. Analyzes the opportunities offered by bar code and radio frequency identification (RFID) technology to develop a new type of e-grocery related service, namely vendor-managed inventory (VMI) in the household.The home delivery transportation service is one of the critical resources to the success orfailure of the e-grocery business. In order toturn e-grocery and home delivery service intoa profitable business, the e-grocers have tounderstand the variables affecting the coststructures of the different service concepts [4]. Ultimately, the future of online grocery shopping seems extremely secure. Like any good business idea, a need had been identified and amplified. Indian online grocery shoppers have found buying grocery online convenient, comfortable and hasslefree. Given the pace of life, smartphone penetration and ease of use they offer, it will be a long time before these online grocery platforms can call it a day[2].Online grocery stores are gaining popularity in India due to sheer convenience, ease of shopping and a fast-growing market. Globally, online grocery retail is growing nearly 7 times faster than on-ground formats and the Indian market may soon catch up.[1] The Indian retail industry is estimated to be worth over $\$ 500$ billion (one of the world's top 5 markets) and $30-40 \%$ of the businesses will be in the online retail space over the next 7 years. This presents a great opportunity for any form of e-tailing, especially the e- 
grocery. As of now, grocery e-tailing in India is a largely unorganised space and poses a big challenge in terms of stiff entry barriers.

\subsection{E GROCERY BUSINESS MODEL}

[5] Identified five different e-grocery business models: the integrated model, the third party shipper model, the delivery-only model, the drop-shipping model, and the multi-channel model.

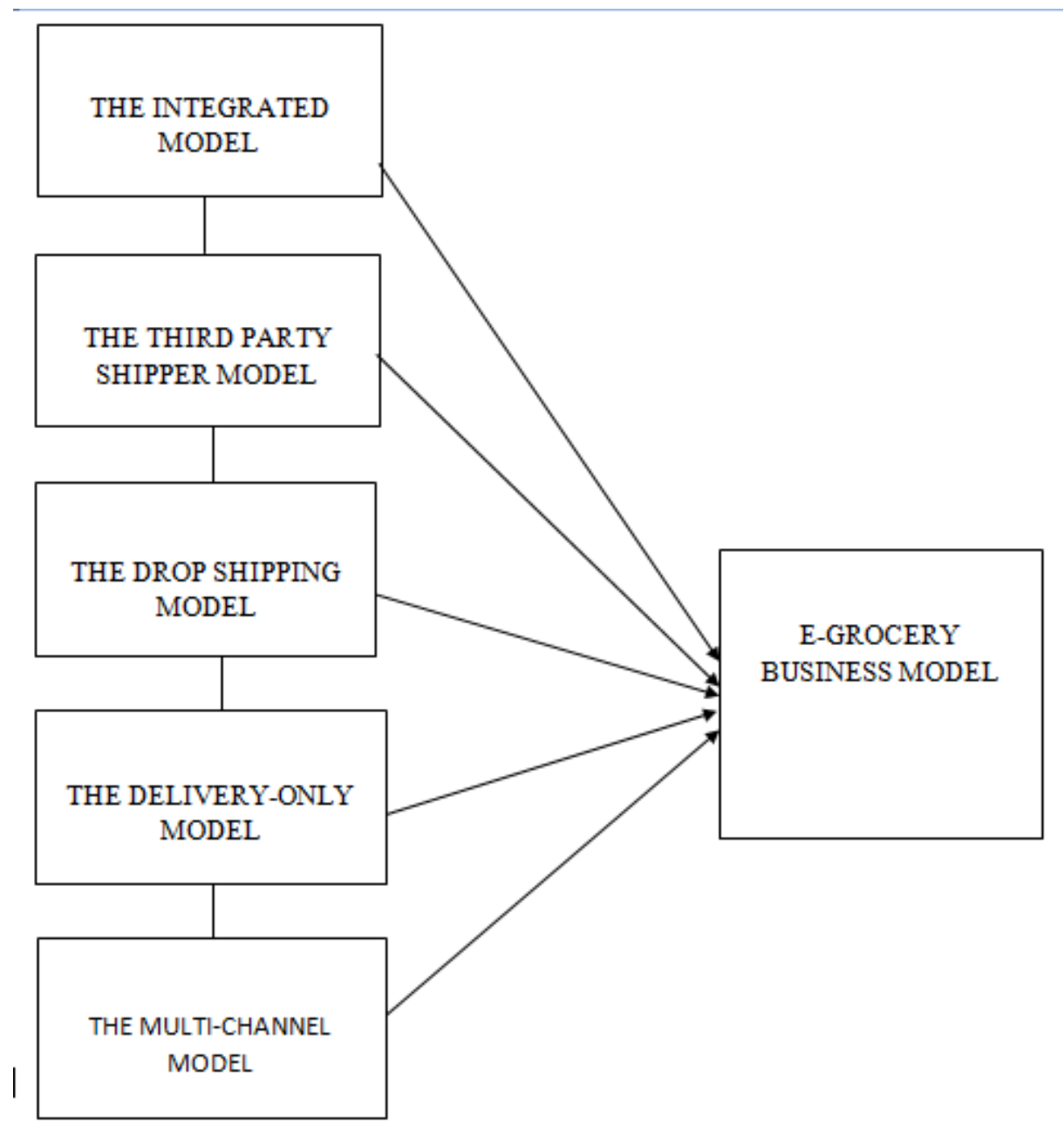

Model I: Five different e-grocery business models

These five broad business models are applicable to e-grocery and e-tailing. These business models are not exclusive of each other and can be implemented jointly or over time. Success or failure of each company will likely depend on the details of implementation of each model, [5].

\section{REVIEW OF LITERATURE}

[4]Success or failure of e-grocery business depends much on timely home delivery transportation. In order to run the business of e-grocery into profits, the e-grocers needs to put the efforts to understand the variables that affects the cost structure of various service concepts. The simulation results show that e-grocery home delivery 
service can actually be as much as 43 per cent cheaper compared to the current costs of customers visiting the store using their own car and spare time. Therefor it is a firm argument in favor of prediction that states the rapid growth of e-grocery business.

India is experiencing a great success of internet usage from last decade which leads to mostly progress in business usage.[6] Research has been undertaken in many aspects of e-business and e-tailing but not in how a developing country looks to develop e-grocery. The main aim of the research is to discover the intention of consumer for shopping of grocery products online.

In India women holds more than $25 \%$ of white collar jobs in various sectors. [7]Now day's professional women are hardworking and those days are no more where women go to market place to buy the groceries. With the emerging trend of internet usage online shopping has become more convenient for especially those women who cannot spare their time to go to purchase daily need items personally.

[8]Discover factors that influence the adoption of buying online grocery by two-step process.In first step exploratory qualitative research is conducted in order to gain the in depth knowledge of buying behaviour of groceries online by consumers. Secondly, large scale quantitative was carried out to confirm the role of situational factors in agitating the begin of online grocery buying. Both qualitative and quantitative results set up the importance of situational factors, for e.g. if there is baby or if there is health problems that can trigger to buy groceries online. Many shoppers tend to discontinue online grocery shopping when the first trigger has become extinct or they have any issue with service. While situational factors are beyond the marketer's control, they could be used as a foundation for marketing communications content and target advertising. The importance of situational factors as triggers for the adoption of online grocery shopping suggests irregular adoption process i.e. carried by situations rather than by a cognitive elaboration and decision. The adoption of online shopping seems to be contingent and may be discontinued when the initiating circumstances change.

The study by [9] examined the perceptions and preferences of Malaysian consumers towards online grocery shopping. It is also examines three (3) important factors in online grocery shopping; cost and charges, time availability and convenience of online grocery shopping, which will contribute to the impact of online grocery shopping. Sample of population for this study were consumers who had some experience in online food retailing, particularly online grocery shopping and also those who have not yet to use internet to purchase grocery products. Result of the study showed that Malaysian consumers were disagreeing on the extra cost and charges of online grocery shopping charged by the online grocers. The same feeling they expressed on the time availability that they have and also the timeused to navigate the online pages.

This study by[10]proposes a new simple model to describe the factors that influence the intention to use internet for food shopping. The results of the study depicts that there are some important variables that affect consumers online purchase attention for e-grocery and these factors are: safety feeling (insecurity affects negatively the intention to use e-shops), comfort (the greater comfort positively influences the intention to use e-shops), access (ease of access positively affects intention to use e-shops) and product selection (better choice positively affects intention to use e-shops for food shopping). The main way of food shopping is still by far the traditional stores. However it seems that the choice of internet shopping is an increasing trend. Especially at ages from 15 to 45 years, middle-income, educated consumers who have completed or are going to complete higher education, online food shopping was reported in the research and the intention to use it was observed in a higher level.

\section{RESEARCH OBJECTIVE}

The objective of the research rises from the problem statement, giving specific idea, and achievable goals. The objective of the above research is to study the customers intentions while buying groceries through online.

\section{RESEARCH METHODOLOGY}

The methodology of the study is based on the secondary as well as primary data. The primary data is collected through a structured questionnaire to elicit the well-considered opinions of the respondents. The 
questionnaire was designed to take collective feedback from regular customers who buy groceries through online. The data is collected from 60 respondents who were highly involved in E-grocery shopping. The data is collected from respondents residing in Chandigarh, Mohali, Panchkula, Ambala, Patiala. Descriptive statistics technique is used to analyze the data with the help of statistical Package for Social Sciences (SPSS - 20).

- $\quad$ Secondary sources- Routine feedback calls with the customers at Sabkuchfresh.com in my internship.

- $\quad$ Primary Data - Questionnaire survey in which responses were gathered by regular customers.

\section{RESULTS AND INTERPRETATIONS}

Table I. Demographic Profile of Respondents

\begin{tabular}{|l|l|l|}
\hline Demographic Profile & Code & Response \\
\hline Gender & & \\
Male & 1 & 33 \\
Female & 2 & 27 \\
Total & & $\mathbf{6 0}$ \\
\hline Age & 1 & 26 \\
$18-30$ & 2 & 23 \\
$31-45$ & 3 & 11 \\
More than 45 & & $\mathbf{6 0}$ \\
Total & 1 & \\
\hline YearlyHousehold Income & 2 & 05 \\
<2Lac & 3 & 20 \\
2lakh-5 Lac & & 35 \\
$>$ SLac & & $\mathbf{6 0}$ \\
Total & 1 & 42 \\
\hline Occupation & 2 & 10 \\
Service & 3 & $\mathbf{6 0}$ \\
Business & & \\
Any Other & & \\
Total & & \\
\hline
\end{tabular}

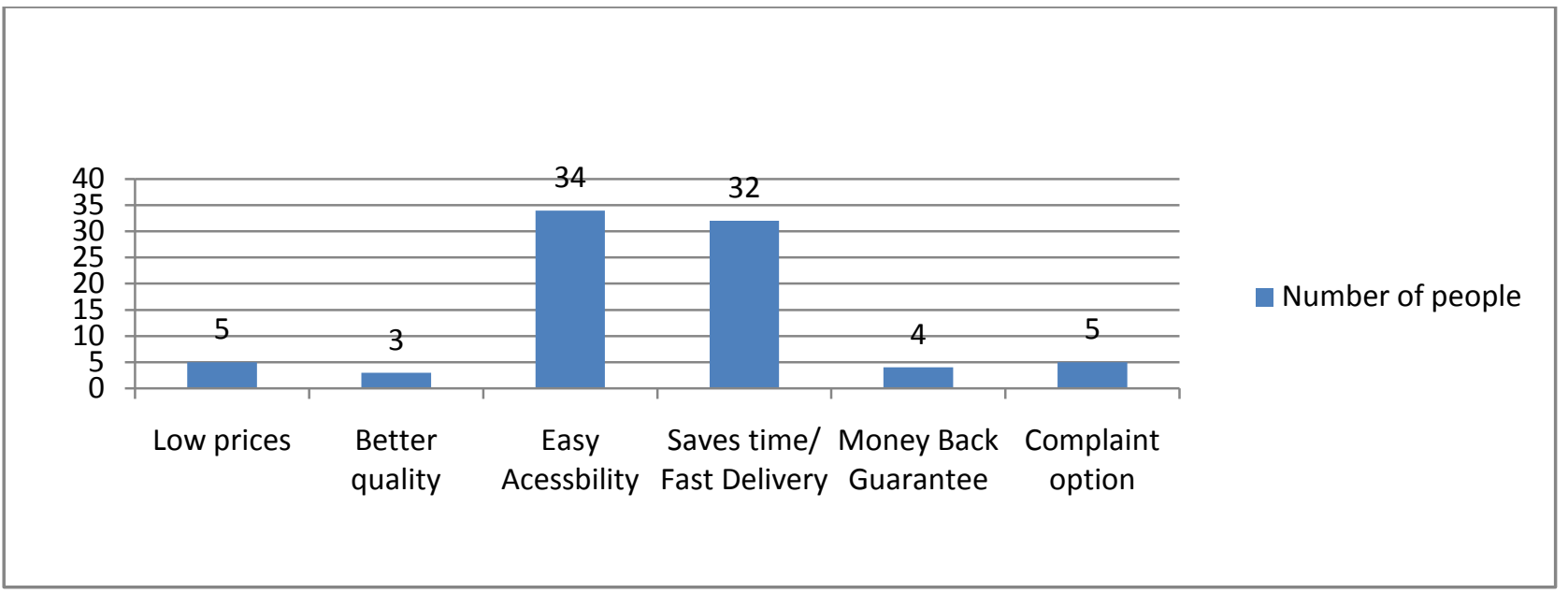

Fig. 1. Basic reasons for E-grocery Shopping 
Out of 60 people most of the people prefer buying fruits and vegetables because of easy accessibility and saving of time.

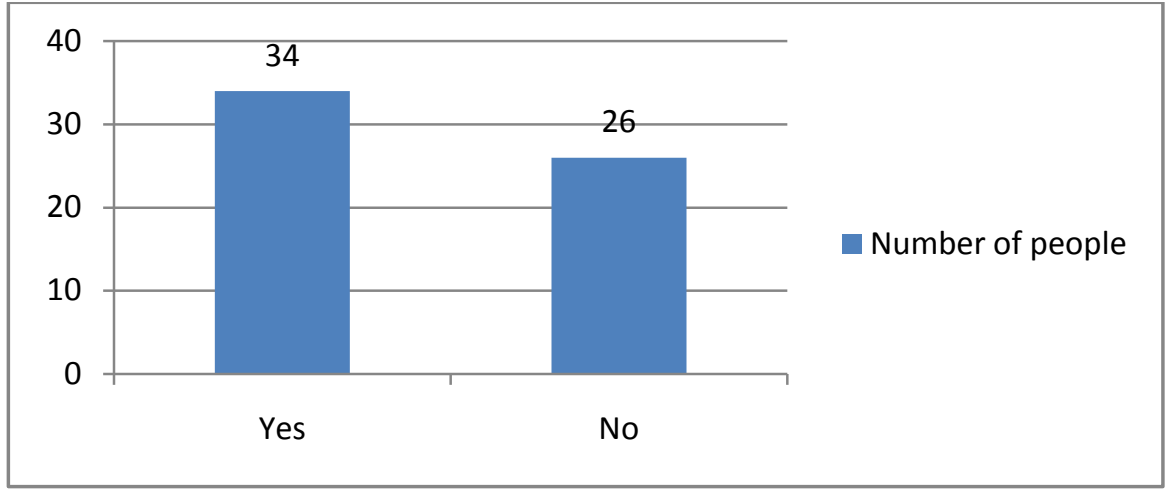

Fig. 2: Satisfaction level towards Quality of products purchased online

Out of 60 people 34 people were satisfied with the products of sabkuchfresh whereas 26 people have problem with the quality of products.

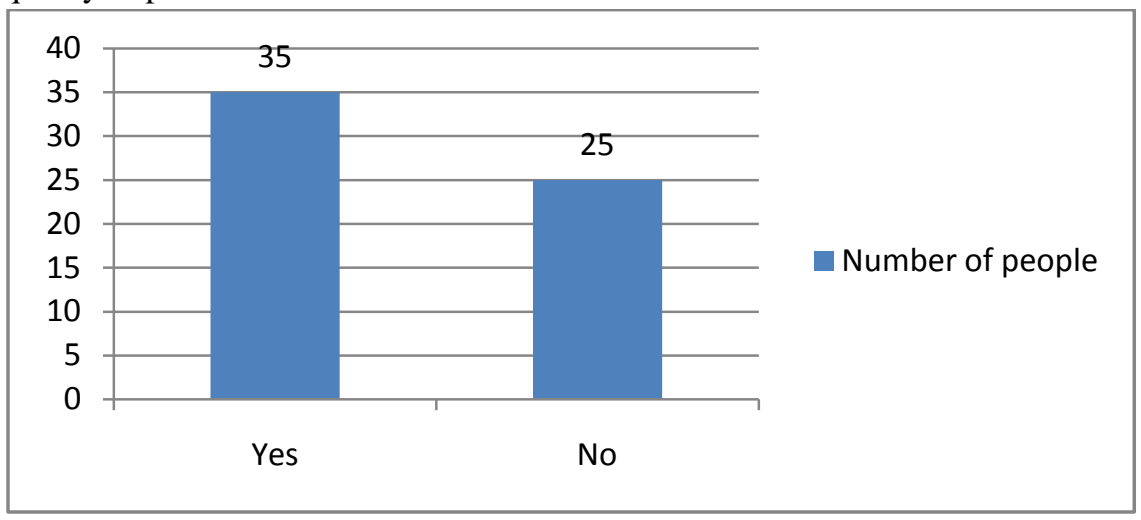

Fig. 3: Receiving your order in chosen delivery slot

Out of 60 customers 25 customers didn't received their order in the mentioned Delivery slot. So the firms in the industry need to improve their delivery process so that Order must be delivered between the given slots.

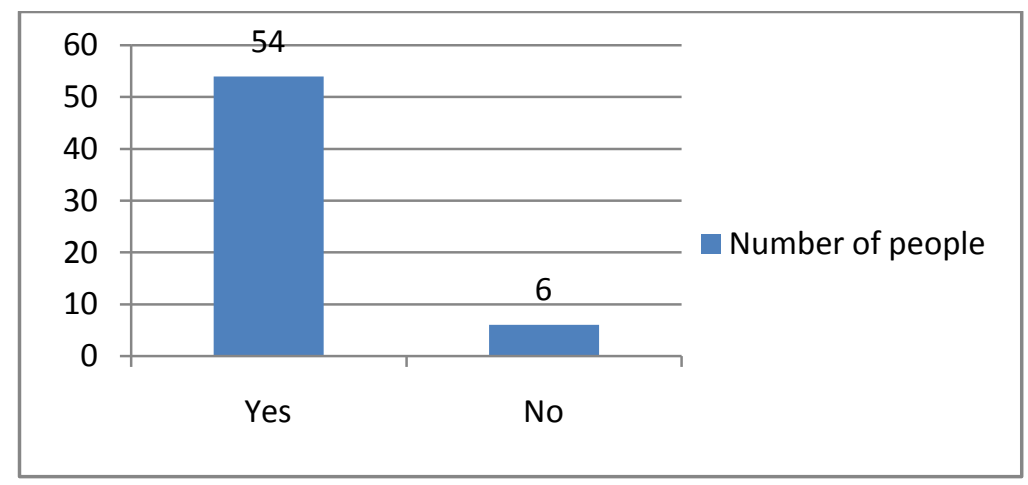

Fig. 4: Customer satisfaction with the packaging of products purchased online. Out of 60 majority of 54 customers were satisfied with the packaging of the products. 


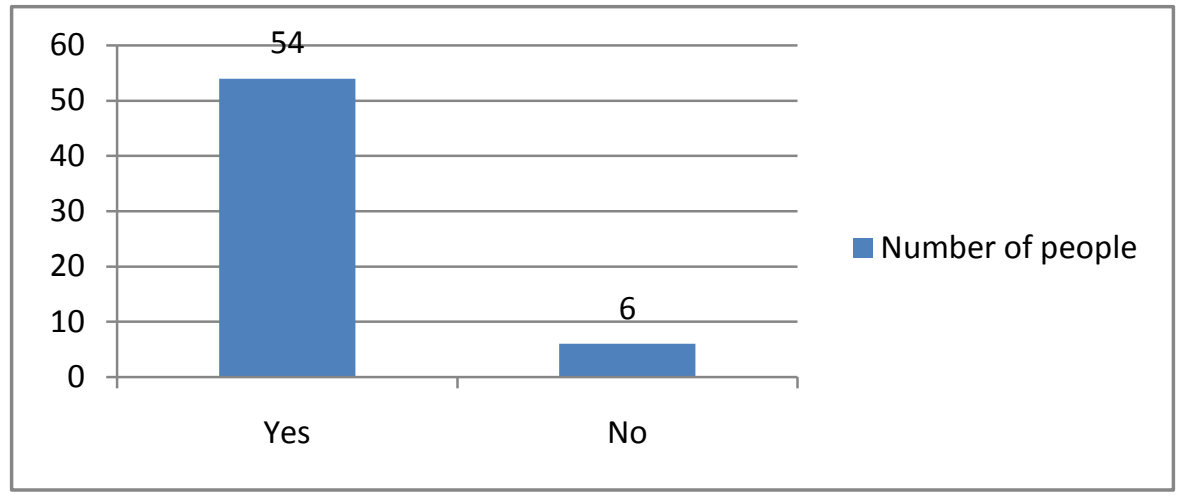

Fig. 5: Recommending online grocery shopping to your family \& friends

Majority of the customer responded yes which shows a positive WOM promotion for the industry.

\section{CONCLUSION}

Online grocery industry is one of the growing industries in India. This particular business model is more popular amongst the people in service profession followed by business class and people retired. The paper strategically analyzed the Indian online grocery Industry. The results of the study depicts that the model is more popular amongst the working women followed by men. The study further reveals that the major reason for purchasing groceries online is saving of time and effort, on average customers for this model are satisfied with the quality of the products received by them, also the sellers are providing customers with option of replacement. The study also depicts the expectation of a customer while buying groceries online and in physical market is totally different. The problem that lies in this model is of delay in scheduled delivery, non-availability of products due to some unavoidable conditions.

\section{REFERENCES}

[1] http://www.businessinsider.in/This-E-grocery-Start-up-Uses-A-Lean-Model-For-Its-Online-Supermarket-In-Talks-To-Raise-SeriesBFunding/articleshow/31184822.cms.

[2] http://www.iamwire.com/2015/07/future-online-grocery-shopping-india/119976

[3] J. Småros, and J. HolmstroÈm," Viewpoint: reaching the consumer through e-grocery VMI". International Journal of Retail \& Distribution Management, 28(2), 2000, 55-61.

[4] M. Punakivi and J. Saranen, "Identifying the success factors in e-grocery home delivery", International Journal of Retail \& Distribution Management, 29(4), 2001, 156-163.

[5] Y. Duval, "Emerging business models in the e-grocery industry", Proc. $3^{\text {rd }}$ European Conference of EFITA, Montpellier, France, 2001, 427432.

[6] K.V. Pandya, J. Vallabhaneni and C. Seow, "E-grocery in India: a comparison with UK", International Journal of Indian Culture and Business Management, 5(3), 2012, 233-258.

[7] L. Zhou, L. Dai and D. Zhang, "Online shopping acceptance model-A critical survey of consumer factors in online shopping", Journal of Electronic Commerce Research, 8(1), 2007, 41.

[8] C. Hand, F. Dall'Olmo Riley, P. Harris, J. Singh and R. Rettie, "Online grocery shopping: the influence of situational factors", European Journal of Marketing, 43(9/10), 2009, 1205-1219.

[9] Z. M. M. Zaini, N. Ramli, F. A. Ghani, A. Samsudin, M. Hamid, K. Jusoff and M. Musa, "Online grocery shopping: The affect of time availability on Malaysian consumer preferences", World Applied Sciences Journal, 12, 2011, 60-67.

[10] K.M. Chatzis, V.F. Panagiotopoulos, and V. Mardiris, "Factors Affecting Consumer Intention to use Internet for Food Shopping, Proc. $9^{\text {th }}$ MIBES Int. Conf. 30/5-1/6, 2014, 206-215. 